\title{
A USP COMO CLIENTE DA PRÓPRIA USP: RELATO DE CASO DO VÍDEO INSTITUCIONAL DA FACULDADE DE MEDICINA DE RIBEIRÃO PRETO
}

USP AS ITS OWN CLIENT: CASE REPORT OF THE INSTITUTIONAL VIDEO OF MEDICAL SCHOOL OF RIBEIRÃO PRETO

*Antonio Pazin Filho, **Almir Almas, ***Eduardo Tessari Coutinho, ****Maria de Lourdes Veronese Rodrigues

\section{RESUMO}

O objetivo deste artigo é relatar a experiência da Faculdade de Medicina de Ribeirão Preto (FMRPUSP) ao contratar alunos da Escola de Comunicações e Artes (ECA-USP) para desenvolver um vídeo para divulgação de informações sobre essa escola médica. A experiência demonstra a possibilidade de se utilizar serviços da própria USP, dando, ao mesmo tempo, oportunidade de estágio para os seus alunos de graduação, desde que haja aprovação da respectiva Comissão de Graduação. Os autores sugerem que este tipo de cooperação deva ser estimulado e ampliado.

Palavras-chave: USP. Golaboração. Integração.

\section{ABSTRACT}

The aim of this article is to report the experience of FMRP-USP in contracting students from Communication and Arts School (ECA-USP) to develop an institutional video for divulgation. This experience demonstrates the possibility of utilization of services between sectors of the same university, giving, at the same time, opportunities for training of undergraduate students, when approved for the Committee for Undergraduate Affairs. The authors suggest that this type of cooperation must be stimulated and expanded.

Key words: USP. Collaboration. Integration.

\footnotetext{
* Professor associado da Divisão de Emergências Clínicas do Departamento de Clínica Médica da Faculdade de Medicina de Ribeirão Preto da Universidade de São Paulo (FMRP-USP), membro da Comissão de Cultura e Extensão Universitária (CCEx) da FMRP-USP - Av. Bandeirantes, 3900 - Ribeirão Preto - SP - I4048-900-e-mail: apazin@fmrp.usp.br. ** Professor doutor do Departamento de Cinema, Rádio e Televisão da Escola de Comunicações e Artes da Universidade de São Paulo (ECA-USP), membro da CCEx da ECA-USP - e-mail: alalmas@usp.br. **** Professor doutor do Departamento de Artes Cênicas da ECA-USP, presidente da CGEX da ECA-USP - e-mail: edumimo@usp.br. **** Professora titular do Departamento de Oftalmologia, Otorrinolaringologia e Cirurgia de Cabeça e Pescoço da FMRP-USP, presidente da CGEx da FMRP-USP Faculdade de Medicina de Ribeirão Preto da Universidade de São Paulo - e-mail: mdlvrodr@fmrp.usp.br.
} 


\section{INTRODUÇÃO}

A Universidade de São Paulo (USP) é constantemente cobrada para ampliar suas vagas em cursos de graduação de modo a melhorar o aproveitamento dos altos recursos investidos em sua infraestrutura. Em que pese o valor do conhecimento gerado pela pesquisa realizada, as modificações recentes da sociedade têm ampliado a fiscalização da qualidade do produto final, ou seja, a qualidade de seus egressos. A atenção crescente ao perfil do egresso e de sua inserção no mercado de trabalho são exemplos dessa preocupação, que se reverte em pressão sobre o corpo docente dos diversos cursos.

A inserção profissional é de difícil avaliação por diversos motivos, sendo um fator contumaz a variabilidade das condições inerentes à profissão. Por exemplo, nas profissões ligadas à saúde, o egresso cada vez mais se torna funcionário contratado de alguma instituição, modificando a tendência histórica de se tornar profissional liberal. Do mesmo modo, em outras profissões, a tendência global é que o aluno se torne um funcionário de um negócio já estabelecido ao invés de se tornar seu próprio patrão. Essa tendência faz com que cada vez mais seja exigido do egresso experiência profissional prévia ou prática profissional supervisionada na forma de estágios relacionados ao produto resultante diretamente da atividade profissional. Assim, do mesmo modo que o currículo de um pesquisador deve conter experiência em pesquisa, o do egresso deve conter experiência profissional na forma de estágios ou carga horária de atuação profissional. Essa exigência passa a oferecer vantagem competitiva no processo de absorção pelo mercado de trabalho.

É lógico que todos os cursos oferecidos pela USP contemplam a prática profissional supervisionada, principalmente nos estágios finais. No entanto, a inserção profissional exige um diferencial do aluno, uma experiência extracurricular. A importância disso pode ser avaliada pelas modificações curriculares que estão responsabilizando o indivíduo cada vez mais pela sua formação, à medida que incluem tempo livre para que desenvolva as atividades necessárias para a atuação profissional pretendida. Prover experiências dessa ordem não é fácil e muitas vezes os alunos acabam exercendo essas atividades na própria unidade formadora, ou buscando experiências extramuros, cuja mensuração do efeito é mais qualitativa do que quantitativa.
Finalmente, quando essas atividades acontecem fora dos muros da unidade formadora, geralmente se buscam atividades em unidades semelhantes; assim ocorre, por exemplo, com os alunos de Medicina da FMRP-USP, que buscam estágios em outras escolas de Medicina.

Neste artigo, iremos relatar a experiência da FMRP-USP ao contratar alunos de outra unidade da universidade, a Escola de Comunicações e Artes (ECA), para desenvolver um vídeo institucional para divulgação. A experiência abre a possibilidade de se utilizar serviços da própria USP para que suas necessidades sejam alcançadas, ao mesmo tempo em que abre toda uma nova oportunidade de estágios para os seus alunos de graduação, caso essa atividade seja contabilizada como parte de cumprimento dos requisitos de estágio.

A FMRP é uma das unidades mais tradicionais da USP, tendo completado 55 anos e já formado mais de 5 mil médicos. Tem projeção internacional e, em 20IO, foi a segunda maior unidade em termos de produtividade em pesquisa de toda a USP, apresentando número de pós-graduandos superior ao seu número de graduandos. A partir de 2002, passou a oferecer cinco novos cursos (Fisioterapia, Fonoaudiologia, Terapia Ocupacional, Nutrição e Informática Biomédica), além dos cursos de Medicina e de Giências Biomédicas. Essas e outras mudanças institucionais geraram necessidade de divulgar informações, atraindo alunos para seus cursos e propiciando material para que seus docentes divulguem a unidade nos âmbitos nacional e internacional.

Essa necessidade se concretizou na necessidade de participar da Feira das Profissões, criada pela USP para divulgar seus cursos frente à enorme taxa de abandono. Para esse evento, foi solicitado à unidade um vídeo institucional para difundir os seus valores e prover informações sobre as condições de formação que os alunos de graduação e pós-graduação encontrariam na FMRP.

$O$ vídeo institucional anteriormente utilizado pela FMRP, assim como o primeiro vídeo desenvolvido na instituição, foi realizado por profissionais de documentação cientifica, sendo constituído em sua maior parte por entrevistas do diretor da unidade e dos presidentes de suas comissões. Dessa forma, o vídeo se desatualizou rapidamente, pois, cerca de um ano após a sua edição, já houve mudança da diretoria e das presidências das comissões. Além disso, as imagens colhidas foram restritas a tomadas externas gerais e gravação dos laboratórios nos quais se realizaram as entrevistas. E também, o vídeo tinha duração excessiva, não sendo possível sua 
divulgação pela rede mundial de computadores e sendo pouco atrativo para o público em geral. Finalmente, o vídeo era narrado em português, não dispondo de legendas, o que impossibilitava a sua divulgação internacional. Em que pesem essas limitações, sem dúvida esses vídeos se constituíram em marcos na história da FMRP, pois alertaram a instituição sobre a necessidade de profissionalizar a divulgação de seus valores.

Preocupada com essa necessidade, a Comissão de Cultura e Extensão (CGEx) da FMRP solicitou verba à Pró-Reitoria de Cultura e Extensão Universitária da USP para a elaboração e confecção de um novo vídeo institucional. Na elaboração desse novo vídeo, a instituição tinha a intenção de solicitar a ajuda de profissionais da área de comunicação.

\section{MATERIAL E MÉTODOS}

Frente à aprovação do projeto, a CGEx-FMRP deu início aos trabalhos, constituindo uma comissão de docentes representantes dos seus diversos cursos. O primeiro passo foi a busca de produtoras locais que pudessem desenvolver o vídeo, o que se constituiu na dificuldade maior do projeto, pois a dotação orçamentária disponível era incompatível com os preços de mercado. Muitas produtoras se negaram a fornecer cotação de preços e outras apresentaram orçamento que superava em muito o disponível.

Para se contornar esse problema, surgiu a idéia de entrar em contato com a ECA-USP em São Paulo através do presidente de sua CGEx, o professor doutor Eduardo Coutinho. O que se propunha é que alunos da instituição desenvolvessem o projeto a preço de custo, repassando-se o orçamento disponível para aquela instituição para cobrir os gastos com filmagem, produção e transporte. Através desse contato, a GCEx-ECA repassou o pedido ao Departamento de Ginema, Rádio e Televisão (CTR) via seu representante na comissão, o professor doutor Almir Almas. O CTR, por sua vez, promoveu um concurso entre seus alunos e dentre as oito propostas apresentadas, foi selecionada uma que atendia as condições necessárias. Ficava claro que os alunos desenvolveriam o projeto sob supervisão docente, mas o desenvolveriam como profissionais atuantes no mercado. Um docente da FMRP (o primeiro autor) seria o interlocutor da unidade para dirigir e organizar os trabalhos.
O processo foi constituído por várias etapas, sendo iniciado pela reunião da Comissão de Vídeo com o professor orientador do vídeo e os alunos que desenvolveriam o projeto (Richard Dantas, produtor, roteirista e diretor; Emilio Gonzalez, fotógrafo e editor; e Nicol Alexander, assistente). Ressalta-se que a primeira reunião foi realizada via conexão às salas de videoconferência da EGA e a da FMRP, mostrando também o uso dessa ferramenta tecnológica nas possibilidades de comunicações entre as unidades da universidade. Nessa etapa ficou estabelecido que o vídeo fosse o mais atemporal possível, focando a instituição e não o seu corpo docente. Descartaram-se entrevistas com docentes como partes do filme, embora elas viessem a ser realizadas para se determinar os valores da FMRP. Também ficou estabelecido que a duração do vídeo não ultrapassasse oito minutos frente ao orçamento disponível, impossibilitando o desenvolvimento de um vídeo para cada curso de graduação oferecido. Ao invés disso, optou-se por prover informações sobre todos os cursos no mesmo vídeo. Finalmente, o foco do filme deveria ser seu público externo, entendido como egressos do Ensino Médio interessados nos cursos de graduação oferecidos, em egressos de nível universitário interessados em pós-graduação e no público em geral, tanto nacional como internacional, que desejasse informações sobre a FMRP. Para atender esse último público definiu-se que o vídeo deveria ser bilíngue (português e inglês), disponibilizando também o conteúdo em legendas, de modo a possibilitar sua exibição em salas de espera e outros locais com restrição sonora. Posteriormente optou-se por produzir o vídeo em formato trilíngue, ofertando também o espanhol como idioma. Para suprir as necessidades não previstas de apresentação trilíngue, a diretoria da FMRP complementou o custo com verba própria.

Passou-se então à fase de pesquisa, em que os alunos tiveram acesso à versão anterior do vídeo, ao material sobre a história da instituição, seus relatórios gerenciais de produtividade e entrevistaram seus dirigentes. Através desse processo de pesquisa, estabeleceu-se uma primeira versão do roteiro do filme, que foi analisada pela Comissão de Vídeo e por membros da CGEx. O roteiro sofreu várias correções (diversos tratamentos) até que se obteve a versão final. Todas as versões do roteiro foram também discutidas dentro do GTR, tendo a orientação dos professores Almir Almas e Luis Fernando Angerami Ramos. 
A fase de filmagem incluiu tomadas externas e internas de diversos aspectos da FMRP para ilustrar o roteiro acordado. No total, os alunos se deslocaram para Ribeirão Preto para quatro seções de filmagem, sendo três delas para a confecção da versão inicial e uma última ocasião para a obtenção de uma versão final. A versão preliminar foi apresentada à Comissão de Vídeo, à CGEx, ao diretor e ao vice-diretor da FMRP, sendo adaptada de acordo com as críticas realizadas até que se obteve a última versão.

A etapa final foi a produção de versões do vídeo para disponibilização via rede mundial de computadores e para um DVD com créditos adicionais que permitisse a escolha de idioma e de legendas nas três línguas selecionadas, o processo de construção do vídeo para resgate histórico, detalhes sobre as atividades das comissões da FMRP e informações sobre os cursos em maior profundidade.

Os alunos apresentaram as versões do vídeo aos professores orientadores, que faziam suas considerações e sugestões. Havia discussões com os alunos a respeito dos pedidos e comentários realizados pela FMRP, que, dentro desse processo, atuava como um cliente.

O processo de desenvolvimento foi retardado por prazos do ano letivo tanto dos alunos da FMRP como dos alunos da ECA que desenvolviam o vídeo. Também foi difícil concatenar as agendas dos docentes responsáveis pela elaboração do processo. A transposição da verba entre as unidades e o repasse para os gastos dos alunos com o projeto sofreram entraves burocráticos, que também implicaram em atrasos. É importante que se tire dessa experiência ensinamentos de como lidar com esses trâmites burocráticos interunidades, para que futuros projetos em conjunto sejam realizados de forma mais tranquila.

Finalmente, houve desacordo entre a versão apresentada pelos alunos e o desejo dos docentes da comissão. Esse último aspecto merece destaque, pois os alunos enfrentaram o primeiro atrito profissional, defendendo pontos metodológicos apreendidos durante seu curso de graduação e aprendendo a adaptálos numa situação concreta de interação com o cliente. Entendemos isso como um dos pontos fortes desse processo da parceria entre nossas unidades. Para esses alunos, esse aprendizado ao lidar com um cliente real ajuda muito na compreensão dos procedimentos profissionais que eles irão enfrentar ao se formarem.

\section{RESULTADO}

Em que pesem todas essas dificuldades, o vídeo foi produzido de modo a atender às necessidades da FMRP. Encontra-se disponível no endereço eletrônico da FMRP e em DVDs para distribuição. Todo o processo de desenvolvimento foi arquivado junto à FMRP e ao seu acervo histórico.

\section{DISCUSSÃO}

Um dos principais pontos desse projeto encontra-se no fato de uma unidade da USP oferecer serviços profissionais a outra unidade através de seus alunos. Esse ponto merece destaque porque o produto oferecido à FMRP é um exemplo do que os alunos da ECA são capazes e que, sem dúvida, poderão ofertar à sociedade. É um atestado da qualidade do egresso da USP, à medida que a própria universidade confia em seus alunos para desenvolver produtos de nível profissional. Reforça-se que a acepção da palavra profissional em uso aqui é aquela do domínio da ferramenta da profissão escolhida por esses alunos e que a ela se dedicarão ao sair da universidade; e do esmero na qualidade técnica do produto final apresentado.

Também merece destaque o fato de que a própria USP pode oferecer campo de treinamento para os seus diversos cursos. Isso já é feito de modo informal, mas o método utilizado nesse projeto de contratar alunos para desenvolvimento de um produto mensurável pode fornecer oportunidades de trabalho extracurricular remunerado e documentado, de forma a ser utilizado pelos alunos no seu ingresso no mercado de trabalho cada vez mais competitivo. A experiência aqui descrita pode servir como referencial para que se processos dessa natureza sirvam também como requisitos de estágio para alunos de graduação.

Também merece destaque o envolvimento docente nesse processo, pois a responsabilidade de oferecer um produto à USP é enorme. O compromisso docente com projetos dessa natureza adquire aspecto de responsabilidade similar ao que nossos alunos enfrentarão diariamente como profissionais e estreitam a relação docente-aluno. O processo também é benéfico para a própria USP, pois, como ressaltado, os recursos que foram destinados à FMRP para a elaboração do vídeo foram repassados para a ECA, ou seja, para a própria USP, 
implicando em economia de recursos.

O projeto descrito é relativamente pequeno frente ao que pode ser atingido. Por exemplo, por que alunos de Medicina não podem auxiliar no atendimento de Medicina do Trabalho em diversas unidades da USP, desde que supervisionados, reduzindo os custos da universidade com as exigências cada vez maiores da legislação trabalhista? A experiência que esses alunos teriam com esse tipo de atividade seria mensurável pelos indicadores da própria universidade e promoveriam um compromisso do curso de Medicina com atuação profissional para a própria USP. O custo desse serviço poderia ser repassado à unidade, fomentando projetos que se encontram paralisados por falta de recursos. O mesmo pode ser dito de projetos de Arquitetura e Engenharia. Os custos com advocacia trabalhista são enormes e a USP forma os melhores advogados do país. As possibilidades são inúmeras, mas irão requerer esforço e preparo da universidade e seus docentes.

Vale ressaltar que os próprios alunos sentem essa necessidade de desenvolver atividades com maior responsabilidade. São exemplos dessa necessidade a formação de Ligas de Assistência, nas profissões ligadas à saúde, e as Empresas Juniores, que surgem em diversos cursos de ciências exatas. Essas iniciativas estudantis devem ter supervisão obrigatória, pois, por mais competentes que sejam nossos alunos, ainda não têm direitos legais de assinar seus próprios projetos ou de se responsabilizar por seus pacientes. Mas a supervisão dessas entidades recai sobre docentes que o fazem de modo voluntário ou mesmo por outros profissionais ligados informalmente à universidade. $\mathrm{O}$ desinteresse docente se deve em muito à falta de incentivo da universidade para esse tipo de atividade, que não pode ser documentada e, portanto, não pode ser valorizada em termos de carreira docente. A regularização desse tipo de atividade nos moldes do que se observou nesse projeto pode corrigir essas falhas e mesmo questões controversas como remuneração docente por projetos poderiam e deveriam ser abordadas. Se a universidade paga por serviços externos que poderiam ser realizados por profissionais que a compõem, porque não utilizá-los e repassar o justo valor de seu trabalho?

\section{CONCLUSÕES}

Frente a todas essas características, o desenvolvimento do vídeo da FMRP abre novas possibilidades de atuação para a USP, que devem ser facilitadas e ampliadas. Sem dúvida, confiar em seus próprios alunos para atender suas necessidades é a maior prova que a USP pode dar da qualidade dos serviços que oferece à sociedade.

\section{AGRADECIMENTOS}

Os autores agradecem a todos os que colaboraram para a realização do Vídeo Institucional da Faculdade de Medicina de Ribeirão Preto:

- Professor doutor Benedito Carlos Maciel, Diretor da FMRP-USP

- Professor doutor Geraldo Duarte, Vice-Diretor da FMRP-USP

- Equipe da ECA-USP: Richard Dantas (produtor, roteirista e diretor), Emilio Gonzalez (fotógrafo e editor), Nicol Alexander (assistente), e professor doutor Luis Fernando Angerami Ramos (co-orientador)

- Membros da Comissão de Cultura e Extensão Universitária da FMRP-USP

- Professor doutor Fernando de Queiroz Cunha, Presidente da Comissão de Pesquisa da FMRP-USP

- Professor doutor Francisco José Candido dos Reis, Presidente da Comissão de Graduação da FMRP-USP

- Professor doutor Carlos Gilberto Carlotti Junior, Presidente da Comissão de Pós-Graduação da FMRP-USP

- Professor doutor Klaus Hartmann Hartfelder, Presidente da Comissão de Relações Internacionais da FMRP-USP

- Maristela Medeiros Santos da Silva, Secretária da Comissão do Vídeo Institucional

- Membros da Comissão Organizadora Pró Vídeo Institucional da FMRP-USP

- Professora doutora Marisa de Cássia Registro Fonseca, Coordenadora da CoC de Fisioterapia

- Professora doutora Marisa Tomoe Hebihara Fukuda, Coordenadora da CoC de Fonoaudiologia

- Professor doutor Joaquim Cezar Felipe, Coordenador da CoC de Informática Biomédica 
- Professora doutora Claudia Maria Leite Maffei, Coordenadora da CoC de Medicina e Ciências Biológicas - Modalidade Médica

- Professora doutora Paula Garcia Chiarello, Coordenadora da CoC de Nutrição e Metabolismo

- Professora doutora Regina Yoneko Dakuzaku Carretta, Coordenadora da GoC de Terapia Ocupacional 